\title{
Patterns in species richness and composition of plant families in the Malay Archipelago
}

\author{
P.C. van Welzen ${ }^{1}$, J.W.F Slik ${ }^{1,2}$
}

\section{Key words}

floristic patterns

Malay Archipelago

Malesia

PCO

plant families

species richness

\begin{abstract}
Distribution patterns or the recognition of phytogeographical areas is usually based on the presence and absence of species. The taxa on which the analyses are based remain virtually anonymous. Here we want to determine which Malesian plant families (within the sample) are responsible for species richness and composition patterns. The other aim is to determine whether the different islands groups in Southeast Asia can be grouped into separate phytogeographical areas. A Principal Coordinates Analysis (PCO) showed the presence of three phytogeographical areas within Malesia: The Sunda Shelf (Malay Peninsula, Sumatra, Borneo) in the west, the Sahul Shelf (New Guinea) in the east, and all remaining central areas forming Wallacea. The latter can be divided into two parts (Java and the Lesser Sunda Islands versus the Philippines, Sulawesi and the Moluccas). Only twenty plant families (out of 164 sampled) account for most of the biodiversity on the island groups, both in total and endemic species numbers. These twenty families show a limited number of species richness patterns that are significantly associated with one or several of the detected phytogeographical areas. Only a few plant families were equally common throughout the whole Malesian region. Conservation efforts in Malesia should take this spatial distribution pattern into account in order to maximise preservation of both species diversity and complementarity.
\end{abstract}

Published on 30 October 2009

\section{INTRODUCTION}

The Malay Archipelago, also known as Malesia, ranges from the Malay Peninsula to the Philippines and New Guinea. Van Steenis (1950a) defined it as a phytogeographical area based on 'demarcation knots' in generic distributions. He identified these knots just north of the Thai-Malay border, between Taiwan and the Philippines, and between New Guinea and Australia. Malesia can roughly be divided into three areas, the everwet Sunda (Malay Peninsula, Sumatra, Borneo) and Sahul Shelfs (New Guinea) and in between these two Wallacea (Philippines, Sulawesi, Java, Lesser Sunda Islands, Moluccas) with generally a dry monsoon (Van Welzen et al. 2005). Wallacea can also be roughly defined as the area between the two most extreme variants of Wallace's line (see George 1981, for a short history of Wallace's line), the western Merrill-Dickerson or Huxley-line, and the eastern Lydekker's line. The erratic position of Java will be discussed later. The island areas such as Borneo, the Philippines, etc., and the Malay Peninsula form the most commonly used and smallest phytogeographical areas (Van Steenis 1950a, George 1981, Van Welzen et al. 2005).

Van Welzen et al. (2005) recently reviewed Wallace's line and based on botanical evidence they concluded that Malesia is not simply split into two halves by this line, but that the central part of Malesia deserves the status of a separate phytogeographical area. They presented three lines of evidence: Numbers of endemic species, the most common distribution patterns, and a Principal Component Analysis based on species presence on the different island groups.

The sample on which these analyses were based has recently been expanded with the species rich and ecologically important Moraceae, which contains the figs (Ficus spp). Here we repeat

\footnotetext{
National Herbarium of the Netherlands, Leiden University Branch, P.O. Box 9514, 2300 RA Leiden, The Netherlands.

2 Xishuanbanna Tropical Botanical Garden, Chinese Academy of Sciences, Menglun, Yunnan, China.
}

part of their analysis to test whether former phytogeographical conclusions are still valid. Furthermore, we document which plant families are mainly responsible for local species richness. Therefore, we address three questions: 1) which phytogeographical areas can be distinguished in Malesia; 2) which of the sampled plant families contribute most to the observed species richness patterns; and 3 ) which families are linked to which phytogeographical areas.

\section{MATERIAL AND METHODS}

\section{Data}

As basic biogeographical units we used the areas indicated by Van Steenis (1950b) and generally used to indicated distributions in Flora Malesiana: the Malay Peninsula, Sumatra, Borneo, the Philippines, Sulawesi, Java, Lesser Sunda Islands, Moluccas, and New Guinea. In the remaining part of this paper we use the abbreviation BU (Biogeographical Unit) to indicate these nine areas. We followed Van Welzen et al. (2005) in distinguishing as higher units the Sunda Shelf (Malay Peninsula, Sumatra, and Borneo); Wallacea (Philippines, Sulawesi, Java, Lesser Sunda Islands, and Moluccas); and the Sahul Shelf (New Guinea) (referred to as CBU, Combined Biogeographical Units)

We created a database with a sample of the Malesian flora by noting the presence per BU of all indigenous species published in the Flora Malesiana Series I (Angiosperms) and Orchid Monographs so far. All cultivated, introduced and escaped species were ignored. In total 164 families, comprising 850 genera and 7043 species were included in the analyses. Per family endemism was counted for both the BU and CBU areas. For each $\mathrm{BU}$ we selected the five families with the highest number of species or endemics (Table 1). 

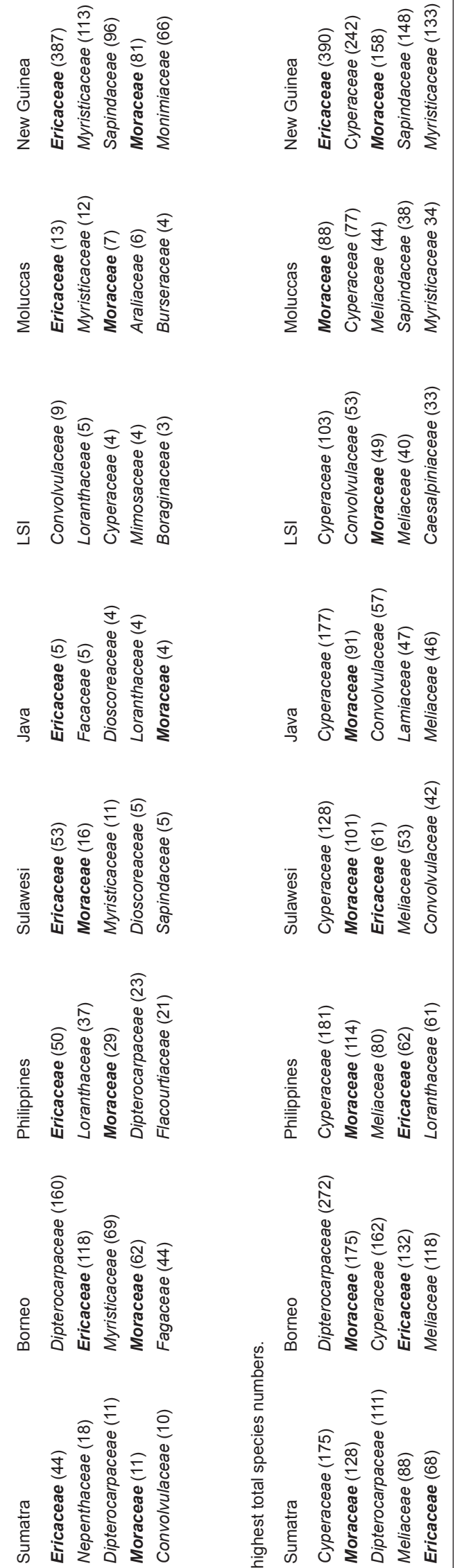

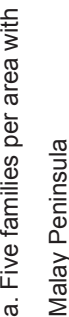

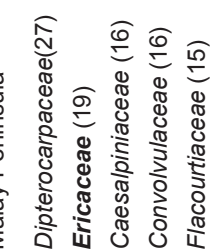

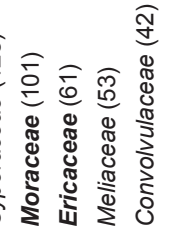

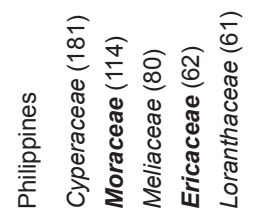

啇

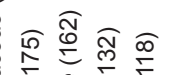

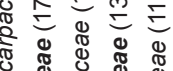
¿ : \&

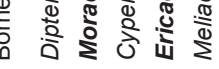

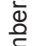

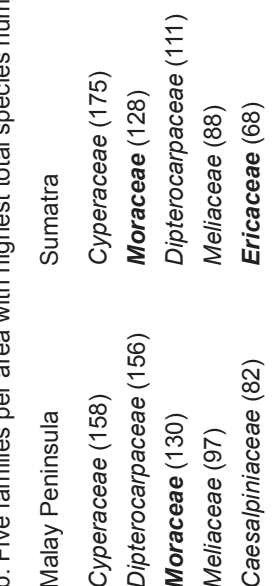

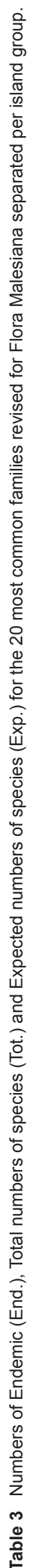

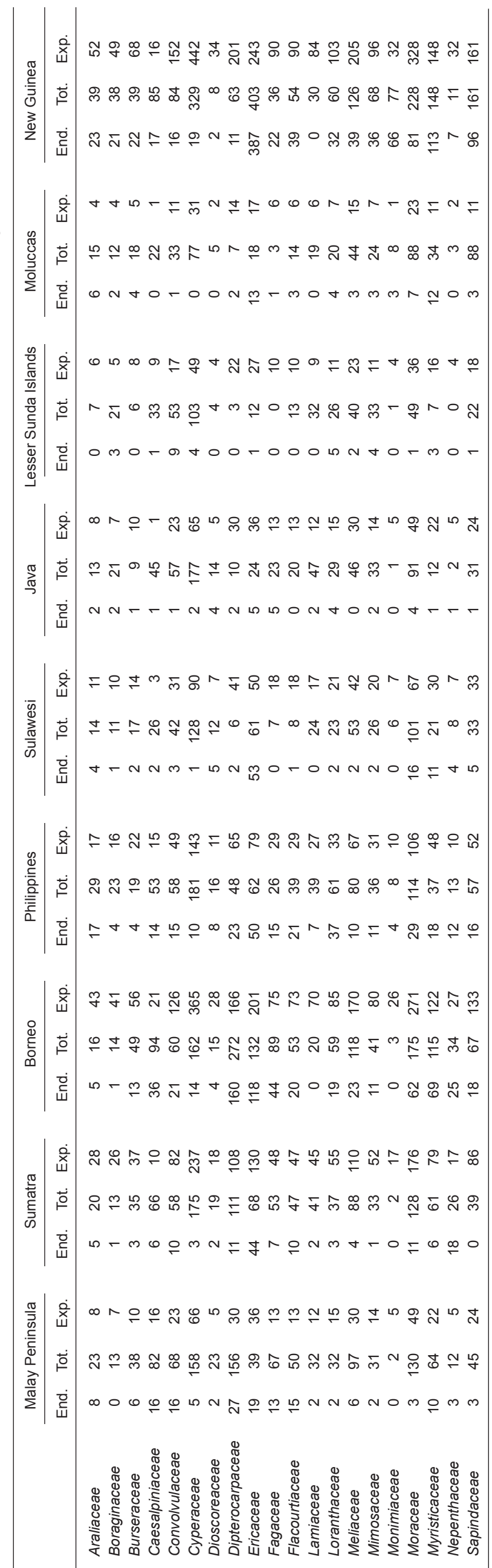


Table 2 Numbers and percentages of endemic species in the Malesian island groups.

\begin{tabular}{|c|c|c|c|c|c|c|}
\hline Part of & Area & Species & Endemics & $\%$ endemics & Size $\left(\mathrm{km}^{2}\right)$ & $\%$ of Malesia \\
\hline \multirow[t]{3}{*}{ Sunda Shelf } & Malay Peninsula & 2030 & 263 & 13 & 132604 & 4 \\
\hline & Sumatra & 1988 & 214 & 11 & 479513 & 16 \\
\hline & Borneo & 2613 & 968 & 37 & 739175 & 25 \\
\hline \multirow[t]{5}{*}{ Wallacea } & Philippines & 1770 & 482 & 27 & 290235 & 10 \\
\hline & Sulawesi & 1169 & 160 & 14 & 182870 & 6 \\
\hline & Java & 1296 & 60 & 5 & 132474 & 4 \\
\hline & Lesser Sunda Islands & 871 & 43 & 5 & 98625 & 3 \\
\hline & Moluccas & 905 & 78 & 9 & 63575 & 2 \\
\hline Sahul Shelf & New Guinea & 2766 & 1489 & 54 & 894855 & 30 \\
\hline
\end{tabular}

\section{Expected species numbers per island}

Earlier analyses (Van Welzen et al. 2005) showed that for the BU's, the relation between area and species number is significantly linear. We used this to compare observed species numbers with the numbers expected on basis of surface area (Table 2). Surface areas of the BU's were taken from Van Steenis (1950b, with the size of New Guinea adjusted to 894855 $\mathrm{km}^{2}$ ). The expected number of species for each plant family in each island was calculated by multiplying the species number with the relative surface area of the BU's (Table 2, last column). Significant deviations between observed and expected numbers of species for the islands were detected with a X2 test. We used a similar approach to compare observed and expected species numbers for the CBU's. Per family we tested whether spatial patterns in species richness were related to the three identified phytogeographical areas (Sunda, Wallacea, Sahul). We tested whether the distribution of observed species richness over the three regions differed significantly from the expected species richness for each of the 20 plant families. Additionally, we tested each of the three regions separately for each plant family to determine the regions where species richness was significantly higher or lower than expected. In all cases, X2-tests were performed with Microsoft Excel.

\section{Principal Coordinates Analysis}

We used a Principal Coordinates Analysis (PCO) with Euclidean distance metric to determine the phytogeographical relations between the islands (Multi-Variate Statistical Package (MVSP) v3.13I, Kovach Computing Services, Anglesey, UK; see manual for explanation). PCO can be viewed as a more general form of Principal Component Analysis (PCA). First we ran a PCO using all species present in the dataset. The analysis was repeated with all $\mathrm{BU}$ specific endemics left out, so that the endemic species could not bias the analysis by creating large distances between the BU's.

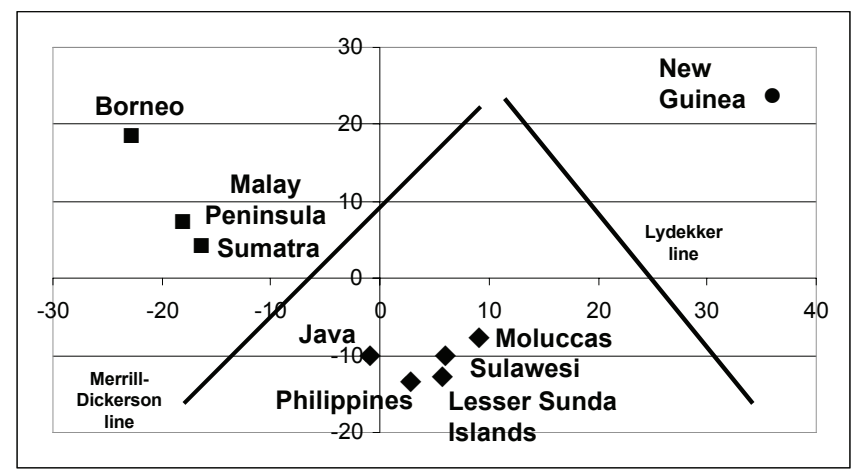

a

Fig 1 a. Principal Coordinates Analysis (PCO) of all sampled species (endemic and non-endemic species together) per island group. The Merrill-Dickerson and Lydecker lines are variants of the Wallace line; b. Principal Coordinates Analysis (PCO) of only the non-endemic species.

\section{RESULTS}

Table 1 shows for each BU the five most common families for total numbers of species and endemic species. All in all, in total only 20 families ( $12 \%$ of all sampled families) are responsible for the most common species.

Seventy percent of all sampled species is endemic in Malesia. For the three CBU's these percentages are: $49 \%$ on the Sunda Shelf, $31 \%$ in Wallacea, and $54 \%$ on the Sahul Shelf. Of the BU's the Philippines, Borneo and especially New Guinea show very high levels of endemicity (Table 2), Java and the Lesser Sunda Islands show low levels of endemism.

The PCO of all species (Fig. 1a) clearly shows three groups of islands. These correspond with the Sunda Shelf, Wallacea, and the Sahul Shelf (except for Java, see discussion). The boundaries correspond with the most western and eastern variants of Wallace's line. The PCO of the non-endemic species (Fig. $1 b)$ separates the Sunda region from all other islands. Within the other islands a roughly linear arrangement is visible from Sahul Shelf (New Guinea) to the Moluccas, Philippines, and Sulawesi in Wallacea. Java and the Lesser Sunda Islands are slightly separated from the rest.

The total and expected number of species and total number of endemics for the twenty most common families are shown in Table 3. These can be divided, based on significant differences between expected and real numbers of species, into a few patterns (Table 4):

- No significant pattern: Five families show no particular preference for any of the three CBU's. These are the Burseraceae, Caesalpiniaceae (Fig. 2a), Flacourtiaceae, Meliaceae, and Myristicaceae.

- Sunda Shelf: Three families (Dipterocarpaceae, Fagaceae - Fig. 2d, Nepenthaceae) show significantly high numbers of species on the Sunda Shelf.

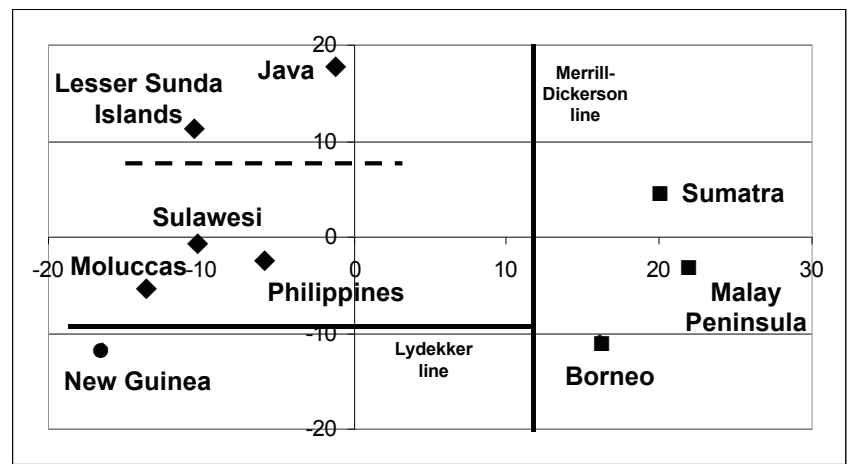

b 
Table 4 Total numbers of species and expected numbers of species per family for the Sunda, Wallacea, and Sahul areas. Total $p=$ significance that species numbers are related to any or a combination of the three areas; Sunda $p=$ significant presense on the Sunda Shelf; Walla $p=$ idem for Wallacea; Sahul $p=$ idem for the Sahul Shelf; in bold the positive correlations (more species than expected). Div. center = Diversification Center; Sn = Sunda Shelf; $\mathrm{W}=\mathrm{Wallacea;}$ $\mathrm{Sh}=$ Sahul Shelf; NS = Non Significant.

\begin{tabular}{|c|c|c|c|c|c|c|c|c|c|c|c|}
\hline \multirow[b]{2}{*}{ Family } & \multicolumn{2}{|c|}{ Sunda } & \multicolumn{2}{|c|}{ Wallacea } & \multicolumn{2}{|c|}{ Sahul } & \multirow[b]{2}{*}{ Total $p$} & \multirow[b]{2}{*}{ Sunda $p$} & \multirow[b]{2}{*}{ Walla $p$} & \multirow[b]{2}{*}{ Sahul $p$} & \multirow[b]{2}{*}{ Div. center } \\
\hline & Total & Exp. & Total & Exp. & Total & Exp. & & & & & \\
\hline Burseraceae & 62 & 63 & 40 & 35 & 39 & 42 & NS & & & & SnWSh \\
\hline Flacourtiaceae & 98 & 95 & 60 & 53 & 54 & 64 & NS & & & & SnWSh \\
\hline Meliaceae & 142 & 153 & 104 & 85 & 93 & 102 & NS & & & & SnWSh \\
\hline Myristicaceae & 152 & 167 & 86 & 93 & 133 & 111 & NS & & & & SnWSh \\
\hline Caesalpinaceae & 146 & 124 & 86 & 69 & 44 & 83 & $=0.0006$ & NS & NS & $<0.0001$ & $(\mathrm{SnW})$ \\
\hline Dipterocarpaceae & 347 & 190 & 61 & 106 & 15 & 127 & $<0.0001$ & $<0.0001$ & $=0.0002$ & $<0.0001$ & $\mathrm{Sn}$ \\
\hline Fagaceae & 133 & 94 & 51 & 52 & 24 & 62 & $<0.0001$ & $=0.0001$ & NS & $<0.0001$ & $\mathrm{Sn}$ \\
\hline Nepenthaceae & 57 & 41 & 22 & 23 & 11 & 27 & $=0.0105$ & $=0.0135$ & NS & $=0.0047$ & $\mathrm{Sn}$ \\
\hline Araliaceae & 38 & 60 & 57 & 34 & 39 & 40 & $=0.0031$ & $=0.0051$ & $=0.0018$ & NS & W \\
\hline Boraginaceae & 21 & 45 & 41 & 25 & 38 & 30 & $=0.0013$ & $=0.0004$ & $=0.0133$ & NS & W \\
\hline Convolvulaceae & 112 & 119 & 97 & 66 & 55 & 79 & $=0.0048$ & NS & $=0.0028$ & $=0.0174$ & W \\
\hline Cyperaceae & 246 & 337 & 260 & 187 & 242 & 224 & $<0.0001$ & $<0.0001$ & $<0.0001$ & NS & W \\
\hline
\end{tabular}

- Wallacea: In this area most families show the relatively highest numbers of species (more than expected): Araliaceae, Boraginaceae, Convolvulaceae, Cyperaceae - Fig. 2b, Dioscoreaceae, Lamiaceae (Labiatae), the half-parasitic Loranthaceae, and Mimosaceae.

- Sahul Shelf: Three families are typical for the everwet Sahul Shelf: Ericaceae (Fig. 2c), Monimiaceae, and Sapindaceae.

\section{DISCUSSION}

The results of the PCO using all species are similar to those presented by Van Welzen et al. (2005), but in that study Borneo was subdivided into three areas (Sarawak, North Borneo, remainder) and the Moraceae were not included. Differences in climate may explain the groupings found in both these analyses. The groupings of areas also reflect the configuration of land (or lack of land) bridges during glacial periods (Morley \& Flenley 1987, Sathiamurthy \& Voris 2006). During glacial periods the Sunda Shelf formed a continuous land-mass with the Southeast Asian mainland, while New Guinea was linked to Australia. However, Wallacea contains only island groups which may have been linked by land bridges (e.g., most Philippine islands were connected), but there were no or hardly any land connections between the island groups. Thus, dispersal of plants was relatively easy on the Sunda and Sahul Shelfs, but limited within Wallacea due to sea barriers. The inclusion of Java in Wallacea may seem odd, as it is geologically part of the Sunda Shelf, but a large part of this island has a dry climate (only West Java is everwet) and that may explain the floristic composition that deviates strongly from the rest of the Sunda Shelf and resembles that of the other areas in Wallacea (Fig. 1a), in particular the Lesser Sunda Islands (Fig. 1b).

Excluding the endemic species from the PCO (Fig. 1b) revealed a somewhat different pattern. The Sunda Shelf is still quite distinct, but especially New Guinea (Sahul Shelf) is closely grouped with the north-eastern areas of Wallacea. This is understandable. New Guinea has more than $50 \%$ endemic species that are ignored in this second analysis. Of the remaining non-endemic species only relatively few (275 out of 1277 ) are shared with Australia (giving rise to the demarcation knot between New Guinea and Australia) or the Pacific Island arcs. Thus all other 1002 species are shared, by necessity, with the Moluccas, Sulawesi, and the Philippines. These shared species clearly indicate dispersal between New Guinea and Wallacea, although the amount of species migrating between Wallacea and the Sunda Shelf is much higher (Van Welzen et al. 2005).
The second PCO (Fig. 1b) also shows Java and the Lesser Sunda Islands to be separate from the other three Wallacea areas. This is probably a result of dispersal during the glacial periods when Java and Bali (the most western island of the Lesser Sunda Islands) were connected to the then dry Sunda Shelf (Morley \& Flenley 1987, Sathiamurthy \& Voris 2006), while the other Lesser Sunda Islands were connected by land bridges and only separated from Java and Bali by a narrow strait. The whole southern part of the dry Sunda Shelf had a dry monsoon climate ('savannah corridor'), allowing drought preferring/resistant species (generally pioneer species, e.g. the herbaceous families Boraginaceae and Lamiaceae) to disperse from Asia to Java and the Lesser Sunda Islands (Java and the Lesser Sunda Islands share 88 species with Southeast Asia mainland that are absent in the rest of Malesia). During interglacial periods, when the island groups were separated by water, the drought preferring species disappeared from the everwet Sunda Shelf while they persisted in southern Wallacea, resulting in a disjunct distribution between Southeast Asia mainland and Java/Lesser Sunda Islands. Probably, several of the drought preferring/resistant species dispersed further into Wallacea, or followed another route (via Taiwan and the Philippines), which explains the loose grouping of the Wallacea areas.

Comparing the observed numbers of species per island group with a calculated expected number related to area size helped detecting patterns between the CBU's and the distribution of the plant families. The major exception was the Malay Peninsula. Table 3 shows that almost all families (except Monimiaceae) have more species in the Malay Peninsula than expected. The Malay Peninsula has generally the same number of species as Sumatra, but its surface area is about a fourth of that of Sumatra. Probably the peninsular connection to the southeast Asian mainland, allowing a continuous exchange of species, resulted in a much richer flora than that of the other BU's.

Some of the patterns need comment. The Myristicaceae, classified as showing no significant pattern, are generally regarded as a Sahul oriented family. However, the Myristicaceae have two main peaks of diversity, one in Borneo and another, higher one, in New Guinea. Both areas have a high number of endemic species. The family is uncommon in Wallacea except for the spice islands, the Moluccas.

The Fagaceae are a typical Sunda family. Especially Lithocarpus and Quercus show many (endemic) species on the Sunda Shelf (higher numbers of species on the Malay Peninsula and Borneo). The genus Nothofagus (see also discussion about APG families below) shows a relatively high number of endemic and non-endemic species in New Guinea. However, 

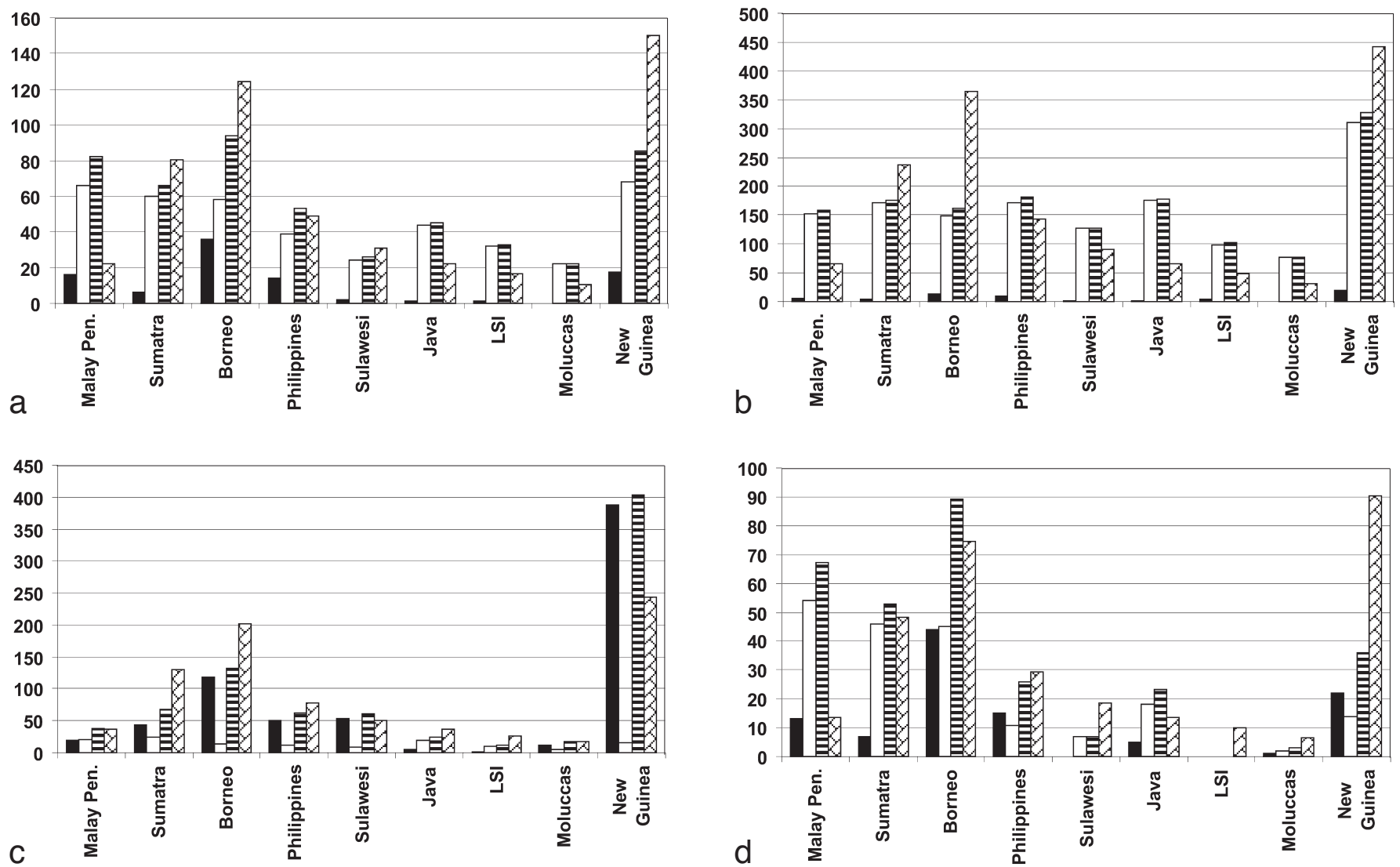

Fig. 2 In the diagrams the numbers of endemics (black bars), Non-endemic species (white bars), Total numbers of species (horizontal stripes) and Expected numbers of species (brick motif) for four different family distribution patterns. a. Caesalpiniaceae - No significant pattern; b. Cyperaceae - Wallacea pattern; c. Ericaceae - Sahul pattern; d. Fagaceae - Sunda pattern.

the New Guinea (Sahul) peak is far less high than the West Malesian peak.

The Cyperaceae have very few endemic species (Fig. 2b), but is one of the most species rich families in most areas, especially in Wallacea. This is counterintuitive, because the Cyperaceae are always associated with wet areas, but the explanation may be that they prefer wet places in an open, savannah vegetation (without dense tree shade) and therefore dominate in areas with a dry monsoon during part of the year.

The Ericaceae (Fig. 2c) show a pattern opposite to that of the Cyperaceae. The Cyperaceae hardly have any endemic species in Malesia (84 out of 394), while the Ericaceae comprise mainly endemics ( 716 out 732 species recorded in Flora Malesiana). The Ericaceae is a family found at higher altitudes, while the Cyperaceae are mainly lowland species; this may explain the difference between both families. The Ericaceae are well represented on the Sunda Shelf, are almost absent in Wallacea, but are extremely species rich, with several genera on the Sahul Shelf.

Many of the 20 families show far more species than expected in Wallacea. Seemingly, for these families speciation in Wallacea is high. A possible explanation is that due to the lack of land bridges during glacial periods dispersal over the islands (crossing open water) could only be accomplished by small numbers of specimens per species, after which isolation during especially interglacial periods resulted in speciation.

Families are often artificial groups, sometimes only recognized because the circumscription is convenient. If this is generally the case then looking for distribution patters at family level is not useful. This problem only plays a limited role here. The families as circumscribed in Flora Malesiana mainly follow the system of Dalla Torre \& Harms (see Van Steenis 1987), and the modern classifications, based on molecular markers, still recognize most of these families as monophyletic groups. In comparison to the Angiosperm Phylogeny Website (APW; Stevens 2006), there are a few differences in the classifications. Caesalpiniaceae and Mimosaceae are part of the Fabaceae in APW, while the Caesalpiniaceae do not form a monophyletic group (though they are a recognizable grade). Two families included in this study fall apart. The Fagaceae are split by APW in a northern hemisphere Fagaceae s.s. and a southern hemisphere Nothofagaceae. This latter split mainly strengthens the West Malesian pattern for the Fagaceae (s.s.) (Fig. 2d). Another family broken up are the Flacourtiaceae, they are now part of the Salicaceae and the Achariaceae, but we did not look into the effect of this on our analysis as seemingly not all genera are well classified yet. The circumscription of a few other families is extended (we list only those with relevance to this analysis, i.e. with species that occur in Malesia): The Sapindaceae now also include the Aceraceae (1 sp. in Malesia) and the Hippocastanaceae (no species in Malesia); the Araliaceae should include the Hydrocotylaceae (in Flora Malesiana still in the Apiaceae/Umbelliferae, three species).

It will be no surprise that the selected 20 families in the sample generally belong to the families with most species and endemics within Malesia. Most of them are in the top 20 of richest families (ranking of all 164 families not shown). Exceptions are the Boraginaceae (place 29 for total species and 31 for endemic species), Dioscoreaceae (place 33 for total and endemic species), Lamiaceae (place 25 and 39, respectively), and the Monimiaceae (place 21 and 20, respectively). Roos et al. (2004) found a similar result while analysing diversity and area size relationships. Thus, the species rich families are usually the families that contribute most to the general distribution patterns. This picture was confirmed by inclusion of the Moraceae, one of the larger families treated so far. 


\section{CONCLUSIONS}

Only a very limited number of families account for most diversity and endemism on the island groups in Malesia. In a way this is not surprising, because they comprise 4397 out of the 7043 species sampled. These twenty families can roughly be assigned to a few biodiversity patterns, but each family has its own unique profile.

The Malay Archipelago is a phytogeographic area that can be subdivided into three regions (Sunda Shelf, Wallacea, and Sahul Shelf). Species richness patterns in plant families are related to these three major areas. Especially, Wallacea seemed to be an important speciation focus for at least half of the families discussed here. Wallacea is floristically still poorly known and threatened by all kinds of human activities. Nature Conservation in all three areas is important, but especially so in Wallacea.

The inclusion of the Moraceae in the sample strengthened earlier conclusions (Van Welzen et al. 2005). Therefore, we are hopeful that the sample, which now includes one quarter of all expected species for Malesia, is large enough to provide significant results for biogeographic analyses

Acknowledgements We are grateful to Peter Hovenkamp and Marco Roos for a positive and constructive feedback.

\section{REFERENCES}

George W. 1981. Wallace and his line. In: Whitmore TC (ed), Wallace's line and plate tectonics: 3-8. Clarendon Press, Oxford.

Morley RJ, Flenley JR. 1987. Late Cainozoic vegetational and environmental changes in the Malay Archipelago. In: Whitmore TC (ed), Biogeographical evolution of the Malay Archipelago: 50-59. Clarendon Press, Oxford.

Roos MC, Keßler PJA, Gradstein SR, Baas P. 2004. Species diversity and endemism of five major Malesian islands: diversity-area relationships. Journal of Biogeography 31: 1893-1908.

Sathiamurthy E, Voris HK. 2006. Maps of Holocene sea level transgression and submerged lakes on the Sunda Shelf. Nat. Hist. J. Chulalongkorn Univ. suppl. 2, 1-43.

Stevens PF. 2006 and onwards. Angiosperm Phylogeny Website, version 7, May 2006. http://www.mobot.org/MOBOT/research/APweb/

Van Steenis CGGJ. 1950a. The delimitation of Malaysia and its main plant geographical divisions. Flora Malesiana, Ser. I, Vol. 1: Ixx-Ixxv.

Van Steenis CGGJ. 1950b. Desiderata for future exploration. Flora Malesiana, Ser. I, Vol. 1: cvii-cxvi.

Van Steenis CGGJ. 1987. Checklist of generic names in Malesian botany. Flora Malesiana Foundation, Leiden.

Van Welzen PC, Slik JWF, Alahuhta J. 2005. Plant distribution patterns and plate tectonics in Malesia. In: Friis I, Balslev $\mathrm{H}$ (eds), Plant diversity and complexity patterns. Local, regional and global dimensions. Biologiske Skrifter 55: 199-217. 
